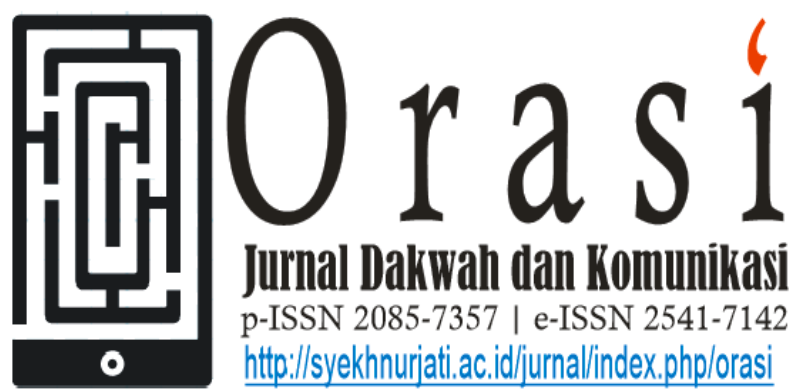

Volume 9 No. 2, PP 75 - 84; November 2018

\title{
MENDEKATKAN PENDENGAR RADIO SIARAN DENGAN DA'I DAN USTADZ MELALUI RADIO DUPLEK
}

\author{
Syaeful Badar \\ Dosen dan Praktisi Penyiaran \\ Fakultas Ushuluddin Adab dan Dakwah IAIN Syekh Nurjati Cirebon \\ viabadar@yahoo.com
}

\begin{abstract}
ABSTRAK
Sekitar tahun 2010an suatu pagi sekitar jam 5 di sebuah pasar tradisonal di Kota Jakarta, terdengar suara da'i dari salah satu frekwensi radio siaran, suara lantang namun mantap, tegas, lugas dan tersusun dengan baik kata dan kalimat yang di ucap, intonasi dan artikulasinya jelas, sehingga membuat yang mender akan terkesima dan takjub mendengar kata demi kata, kalimat demi kalimat yang di ucapkan da'i sejuta umat KH. Zaenudin, MZ dai kondang kembali mengudara lewat ceramahnya di salah satu Radio Siaran swasta di Jakarta, karena memang sejak aktif di Partai Politik ceramah sang da'i tidak pernah di putar di Radio Siaran. Kekuatan Radio Siaran sebagai salah satu kekuatan dakwah di masyarakat telah teruji dan terbukti sampai hari ini, sebut saja KH. Zaenudin, MZ. KH. Syukron Makmun, KH. Nur Muhamad Iskandar, SQ. DR. Hj. Tuti Alawiyah, KH. Abdullah Gymnastiar. Mamah Dedeh (sebelum di TV lebih dulu sebagai penceramah di salah satu Radio Siaran Swasta di Bandung), dan banyak lagi da'i yang di besarkan lewat Radio Siaran.
\end{abstract}

Kata kunci: Radio siaran, studio mini, radio duplek, dakwah

\section{PENDAHULUAN}

Latar Radio Siaran merupakan salah satu media komunikasi yang efektif dan dapat dimanfaatkan untuk kepentingan dakwah dan pendidikan.
Sebagai salah satu media penyiaran public, radio siaran memiliki karakteristik dekat, bersahabat, akrab, mudah di akses serta tidak terbatas pada ruang dan waktu, sehingga memudahkan untuk siapapun 
dapat mendengarkan siaran radio tanpa mengurangi aktifitas yang sedang di lakukan. Kelebihan radio siaran ini yang kemudian sampai saat ini dan kapanpun radio siaran tidak bisa ter saingi oleh media penyiaran yang lain, karena karakteristik radio siaran memang mudah di akses, kapanpun bisa.

Kekuatan radio saiaran sebagai media pendidikan dan dakwah belum di maksimalkan secara program yang ada di radio siaran, hal ini dikarenakan untuk sebuah program siaran yang melibatkan crew dan tim secara masal, tidak hanya persoalan teknis tapi juga persoalan biaya yang cukup besar, apalagi jika bentuk siaran live atau inter aktif antara pendengar dengan narasumbernya. Wajar jika kemudian acara dakwah saiaran ke agamaan selalu terganjal oleh biaya, karena untuk pihak sponsor pun sangat terbatas dan hati-hati jika akan menjadi sponsor acara ke-agamaan, karena jika acara ke-agamaan di siarkan tentunya banyak menyangkut persoalan moral dan etika, sehingga produk yang menjadi sponsorpun tidak bisa semua produk yang di iklankan di radio siaran tersebut. Mungkin kalau kendali teknis dalam program acara di radio siaran bisa teratasim akan tetapi persoalan biaya harus betul-betul menjadi pemikiran kretaif yang harus di munculkan, sehingga kekuatan radio siaran sebagai media pendidikan dan dakwah akan menjadi kekuatan dalam mengembangkan siaran dakwah islam yang rahmatan lil alamin. Kekuatan Radio Siaran sebagai salah satu kekuatan dakwah di masyarakat telah teruji dan terbukti sampai hari ini, sebut saja KH. Zaenudin, MZ. KH. Syukron Makmun, KH. Nur Muhamad Iskandar, SQ. DR. Hj. Tuti Alawiyah, KH. Abdullah Gymnastiar. Mamah Dedeh (sebelum di televisi lebih dulu sebagai penceramah di salah satu Radio Siaran Swasta di Bandung), dan banyak lagi da'i yang di besarkan lewat Radio Siaran.

Sebagai media penyiaran, radio siaran memiliki regulasi peratutan yang cukup ketat sehingga tidak mudah siapapun dapat mendirikan studio radio, karena untuk mendirikan sebuah perusahaan media radio siaran ada beberapa peraturan yang harus di ikuti, diantaranya adanya Undang-Undang Republik Indonesia Nomer 23 Tahun 2002 Tentang Penyiaran, Undang-Undang Republik Indonesia Nomer 36 Tahun 1999 Tenatang Telekomunikasi, UndangUndang Nomer 40 Tahun 1999 Tentang Pers, Peraturan Pemerintah Republik Indonesia Nomer 51 Tahun 2005 Tentang Penyelenggaraan Penyiaran Lembaga Penyiaran Komunitas (LPK). Peraturan Pemerintah Republik Indonesia Nomer 11 Tahun 2005 Tentang Penyelenggaraan Penyiaran Lembaga Penyiaran Publik 
(LPP). Peraturan Pemerintah Republik Indonesia Nomer 50 Tahun 2005 Tentang Penyelenggaraan Penyiaran Lembaga Penyiaran Swasta (LPS). Belum regulasi yang terkait dengan harus adanya ijin usaha dan ijin penggunaan frekwensi sesuai dengan Undang Undang Republik Indonesia Nomer 36 Tahun 1999 Tentang Telekomunikasi pada Bab I Ayat 1 Pasal 5 “ Pemancar Radio adalat Alat Telekomunikasi yang menggunakan dan Memancarkan Gelombang Radio'. Serta Bab IV Pasal 33 Ayat 1 " Bahwa Penggunaan Spekrum Frekwensi Radio dn Orbit Satelit Wajib Mendapatkan Ijin dari Pemerintah. Juga di Undang Undang Republik Indonesia Nomer 32 Tahun 2002 Tentang Penyiaran disebutkan "Spektrum Frekwensi Radio Adalah Gelombang Elektromagnetic yang dipergunakan untuk penyiaran dan merambat di udara serta ruang angkasa tanpa sarana pengantar buatan, menggunakan ranah publik dan sumber alam terbatas Bab I Pasal 1 Ayat 8). Sementara untuk program siaran di radio siaran harus sesuai dengan standar professional radio siaran yang di keluarkan oleh Dewan Kehormatan Kode Etik PRSSNI (Persatuan Radio Siaran Swasta Nasional Indonesia) sebagai salah satu organisasi profesi radio siaran swasta di Indonesia.
Regulasi radio siaran yang begitu ketat sehingga tidak mudah untuk mendirikn industry radio siaran, karena disamping banyak peraturan dan undangundang, juga terbatasnya kanal frekwensi di setiap daerah kabupaten dan kota di Indonesia, hal ini tentunya sangat mempengaruhi radio siaran bisa berkembang secara luas, karena memang pembatasan kanal frekwensi merupakan aturan yang juga di atur oleh International Telecomunication United atau ITU sebuah organisasi dunia yang mengatur kanal dan frekwensi radio siaran, pembatasan kanal frekwensi menjadi salah satu aturan yang di terapkan di Indonesia untuk setiap daerah baik kabupaten maupun kota, sehingga di setiap kota dan kabupaten tidak frekwensi yang sama untuk di gunakan sebagai kanal frekwensi di radio, hal ini tentu menjadi salah satu hambatan karena memang kanal frekwensi harus di atur oleh negara, sehingga penggunaan frkwensi juga harus mendapat ijin yang sesuai prosedur dari pemerintah pusat yang ada di ibukota negara. Regulasi ini tentunya sangat membatasi pendirian baru dari sebuah perusahaan radio siaran, karena di tiap kabupaten dan kota juga di batasi regulasi kanal frekwensi untuk radio siaran, namun di sisi lain dengan perkembangan globalisasi dan munculnya media-media online, maka regulasi siaran 
di radio juga mengalami perkembangan yang pesat, namun sayangnya regulasi kanal frekwensi terbatas, sehingga tidak adanya perusahaan radio siaran yang baru, kecuali di lakukan kerjasama atau pemindahan kepemilikan dari perusahaan radio siaran ke pihak lain, tentunya dengan manajemen yang sama dan kesepakatan yang di buat berdasarkan kebutuhan masing-masing.

.Dalam Undang-Undang Republik Indonesia Nomer 32 Tahun 2002 Tentang Penyiaran telah diatur tentang regulasi lembaga penyiaran, baik lembaga penyiaran swasta, lembaga penyiaran public dan lembaga penyiaran komunitas. Masin-masing lembaga penyiaran tersebut telah di keluarkan peraturan pemerintah untuk mengatur regulasinya sesuai dengan azas dan prosedur yang harus di tempuh, selengkapnya :

1. PP No. 11 Tahun 2005 Tentang Lembaga Penyiaran Publik yaitu TVRI, RRI dan Radio Siaran Pemerintah Daerah.

2. PP No. 50 Tahun 2005 Tentang Lembaga Penyiaran Swasta yaitu TV Swasta, Radio Siaran Swasta, TV Cabel, Radio Siaran On Line dan media elektronik yang lain. Syarat pendiriannya harus PT (Perseroan terbatas), Ijin Usaha,
HO, Ijin Siaran, Sertifikasi Alat dan lainnya.

3. PP No. 51 Tahun 2005 Tentang Lembaga Penyiaran Komunitas, yaitu TV Komunitas dan Radio Komunitas.

Dengan adanya regulasi tersbut di atas maka tidak menutup kemungkinan kanal frekwesi yang masih tersedia hanya di regulasi Lembaga Penyiaran Komunitas atau LPK, itupun tidak mudah karena untuk penyiaran komunitas juga ada syarat dan ketentuannya sebagaiberikut :

1. Berbentuk Badan Usaha (Koperasi, Perkumpulan dan Yayasan)

2. Non-Partisan dan Tidak Komersil

3. Siarannya Khusus Untuk Komunitasnya

4. Modal Usaha Dari Anggota

5. Radius Siaran Hanya 2,5 Kilometer dari lokasi pemancar dengan menggunakan ERP (Effektif Radiated Power) maksimum 50 watt.

6. Mendapat persetujuan penduduk sekitar, paling sedikit sekitar 51\% atau sekitar 250 orang penduduk dewasa secara tertulis dikuatkan dengan persetujuan dari Lurah dan Camat.

7. Mengajukan Ijin Siaran sampai ke Pemerintah Pusat melalui Menteri 
dan harus ada rekomendasi dari

Komisi Penyiaran Indonesia atau KPI

8. Menggunakan Frekwensi di 107, 5 FM keatas.

9. .Untuk lebih lengkapnya ada di PP. No : 51 Tahun 2005.

Lembaga Penyiaran Komunitas kendati masih banyak ruang kanal frekwensi yang tersisa. Namum karena ketatnya regulasi aturan dan syarat-syarat harus di penuhi, sehingga sampai hari inipun masih banyak penyiaran komunitas yang tidak sesuai dengan persyaratan yang di butuhkan.

\section{Mengembangkan Dakwah Melalui}

Radio Siaran dengan Sistem Radio

\section{Duplek}

Duplex atau dua arah adalah komunikasi data yang dilakukan menggunakan dua arah. Dimana antara penerima dan pengirim dapat saling bertukar informasi dan saling berkomunikasi.bertukar data atau informasi antar dua atau lebih pengguna melalui sebuah komputer sehingga masing-masing komputer dapat melakukan pertukaran data. Dalam konteks tehnologi radio siaran istilah Duplek merupakan kegiatan penyiaran radio siaran yang di lakukan di luar studio radio siaran, dengan merelay secara langsung frekewensi dari studio di tempat lain, atau menggunakan obivan yang beraada di lokasi yang jauh dengan studio radio siaran tersebut. Sebagai proses kreattifitas dalam mengembangkan program siaran on air dan off air maka istilah radio duplek menjadi istilah baru untuk mengembangkan istilah relay atau siaran langsung, karena kalau kata relay dan siaran langsung terkesan di batasi oleh waktu-waktu tertentu atau oleh kegiatan yang berbeda-beda, maka untuk lebih mendekatkan pada kegiatan relay yang secara rutin dan terjadwal serta focus pada satu program acara, maka team kreatif dari Radio Maritim 102, 6 FM memunculkan image tentang kegiatan relay siaran menjadi radio duplek, karena terjadi pengiriman dan penerimaan siaran dari tempat yang berbeda.

Sebagai upaya dan dalam rangka mengembangkan dakwah Islam serta untuk mendekatkan komunitas jamaah masjid dengan para ustadz dan da'i dan juga untuk mendekatkan dakwah yang lebih akrab dan inter aktif, maka Masjid Raya At Taqwa Kota Cirebon menggandengan kerjasama dengan PT. Radio Maritim Rassonia 102, 6 FM menggelar program Gelaran Dakwah At Taqwa melalui siaran radio duplek yang di lakukan melalui studio mini di Masjid Raya At Taqwa Kota Cirebon, dipancar siarkan melalui Radio Maritim 102,6 FM. Sebagai upaya kongkrit bersinergi maka di atur syarat dan ketentuan kerjasama 
antara lembaga dakwah masjid dengan sebuah perusahaan media penyiaran, yang tentunya kedua lembaga tersebut memiliki perbedaan yang cukup banyak, karena masjid sebagai lembaga dakwah tentunya tidak sama dengan perusahaan media penyiaran, maka untuk mempersaatukan visi dan misi dalam mengembangkan dakwah di Cirebon kesepakatan kolaborasi antara Masjid Raya At taqwa dan Radio Maritim 102, 6 FM di sepakati langkah-langkah berikut ini :

1. Siaran dari luar atau studio siaran luar bagian dari program siaran radio siaran swasta yang resmi dan berijin.

2. Menempatkan Studio Mini untuk siaran di luar studio.

3. Menjadwalkan salah satu acara yang akan disiarkan secara langsung dari Studio Mini yang ada.

4. At-Taqwa Centre Menyiapkan Ruangan Untuk Studio Mini Beserta Perlengkapannya.

5. At-Taqwa Centre Menyiapkan Crew (Operator, Penyiar dan Narasumber)

6. Radio Maritim Menyiapkan Waktu dan Jam Siar Untuk Studio Mini At Taqwa Centre.

7. Radio Maritim Menyiapkan Tenaga Pendamping Untuk Studio Mini At Taqwa Centre'
Adapun Program Siaran Yang Menggunakan Studio Radio di At Taqwa Centre Adalah Acara Dakwah Yang di Siarkan Setiap Hari Mulai Jam 17.00 sampai Kumandang Adzan Magrib Langsung dari Masjid Raya At Taqwa Kota Cirebon, serta Siaran Pelaksanaan Sholat Jum'at dari Masjid Raya At Taqwa Kota Cirebon.' Untuk Kegiatan Duplek Radio Siaran Antara At Centre Kota Cirebon dengan Radio Maritim 102,6 FM Tidak Ada Pembiayaan. Upaya langkah awal dalam mempersiapkan program Dakwah antara Masjid Raya At Taqwa dan Radio Maritim 102,6 FM Cirebon, maka diadakan berbagai kegaiatan untuk mempersipakn tim dan manajemen, yaitu dengan mengadakan pelatihan tim works Untuk mempersiapkan tim yang akan bertugas maka akan di latih beberapa remaja masjid atau karyawan yang memiliki kans untuk dispersipakan menjadi penyiar atau pemandu acara. Serta menyusun jadwal ceramah yang menjadi narasumber dalam acara Ngaji Jelang Magrib di Studio Mini Masjid Raya At Taqwa dan siap disiarkan langsung di Radio Maritim 102, 6 FM.

\section{Ragam Tema Ceramah program Gelaran Dakwah At Taqwa}

Rahamatan lil alamin menjadi landasan utama dalam menentukan tema dan narasumber yang terlibat langsung 
sebagai penceramah, Masjid Raya Ar Taqwa menjadi penting jika memakmurkan masjid tidak hanya berpihak pada satu kelompok atau golongan tertentu, karena sebagai masjid terbesar dan termegah di wilayah Cirebon, harus mampu mewarnai produk-produk dakwah yang komtemporer dan memiliki visi budaya yang rahmatan lil alamin, sehingga perumusan tema sangat menjadi kekuatan yang harus di maksimalkan, ini menjadi penting karena Masjid Raya At Taqwa tidak mau terjebak pada kekuatan kelompok tertentu serta tidak mau terjebak pada golongan tertentu dan tidak juga terjebak menjadi corong atau juru bicara kepentingan pemerintah, kendati Masjid Raya At Taqwa adalah milik pemerintah Kota Cirebon, karena sejak di bangun pada tahun 1903 Bupati Cirebon Salman Salmon mendirikan Tajug Agung yang sekarang menjadi Masjid Raya At Taqwa adalah Masjid Pemerintah Cirebon pada tahun 1903.

Tidak hanya Masjid Raya At Taqwa, Radio Maritim 106, 6 FM juga memiliki visi agar dakwah di radio siaran memiliki warna yang beda dengan radio siaran yang lain, artinya Radio Maritim 102, 6 FM ingin agar siaran dakwah nya memiliki ciri yang khas yang berbeda terutama dalam menentukan tema dan narasumber. Sebagai radio siaran tertua di Jawa Barat karena Radio Maritim 106, 6
FM didirikan pada tanggal 1 Juni 1965 sejak tahun 1980 menjadi salah radio siaran swasta yang menyiarkan kumandang adzan dhuhur setiap waktu menjelang sholat dhuhur. Menyiarkan suara adzan dhuhur di radio siaran swasta pada dekade tahun 1980an tentunya tidak mudah kecuali dengan keberanian dan kebijakan yang penuh resiko, tetapi itulah yang kemudian di lakukan oleh penanggungjawab Radio Maritim 102, 6 FM, bapak H. Syahrial Aziz dan programmer Radio Maritim 102,6 FM, bapak Evek Sumaedy.

Visi yang visioner inilah yang kemudian mempertemukan dua lembaga yang berbeda, yaitu antara lembaga dakwah masjid dengan lembaga penyiaran radio swasta bisa bersatu dalam visi rahmatan lil alamin untuk bersama-sama mengembangkan dakwah Islam melalui media penyiaran yang berbasis masjid, karena kegiatan program Geladak di adakan di Masjid Raya At Taqwa dan disiarkan melalu Radio Maritim 102, 6 FM yang terpancar di wilayah Cirebon dan sekitarnya, maka disusunlah tema dan nara sumber yang kompeten dan memiliki latar belakang ke ilmuan yang memang di kuasai dan professional.

Tema-tema yang menjadi bahan siaran untuk program acara Gelaran Dakwah At Taqwa meliputi Kajian Hukum Islam, Kajian Tasawuf, Kajian 
Tarekat, Kajian Keluarga Sakinah, Kajian

Kesehatan Reproduksi, Kajian Kesehatan Masyarakat, Kajian Gizi Keluarga, Kajian Islam Aktual, Kajian Budaya Cirebon, Kajian Islam Cirebon, Kajian Islamic Parenting, Kajian Qolbu, Kajian Akhlaq, Kajian Aqidah, Kajian Sejarah, serta kajian-kajian sosial kemasyarakatn yang yang actual dan menjadi trending topic di media. Setiap tema atau kajian di bawakan oleh narasumber atau pakar yang memang professional dalam bidangnya masing-masing, hal ini tentuny akan memberikan warna dan gaya yang beda dengan sajian acara dakwah di radio siaran, yang terbiasa hanya dengan satu tema dan satu narasumber yang sama pada setiap siarannya. Kekuatan tema dan narasumber menjadi cirri yang khas dalam program gelaran dakwah at taqwa yang disiarkan setiap hari pada pukul 16.45 sampai adzan magrib berkumandang, dan disirkan langsung melalui frekwensi 102, 6 FM.

Mengembangkan tema dalam sebuah sajian dakwah di radio siaran, dengan tema yang beragam dalam satu acara di sebuah radio siaran, sangatlah tidak mudah, karena tidak hanya sekedar dibtuhkan sikap berani tetapi juga harus dapat menyakinkan pendengar bahwa siaran dakwah itu tidak hanya membahas tema-tema keagamaan tetapi juga membahas masalah budaya, kesehatan, dan perkembangan sosial masyarakat yang actual. Juga yang terpenting tentunya memadukan dua lembaga yang berbeda dalam satu visi yang sama, mungkin saat ini baru dilakuiokan oleh Masjid Raya At Taqwa dan Radio Maritim 102, 6 Cirebon. Keyakinan ini tentunya bukan hanya sekedar retorika akan tetapi dapaat di buktikan bahwa Program Gelaran Dakwah At Taqwa kerjasama Radio Maritim 102,6 FM dengan Masjid Raya At Taqwa Kota Cirebon telah memasuki tahun ke 4 karena dimulai sejak tahun 2014.

Geladak adalah produk dakwah melenial yang memadukan unsure dialog interaktif dan tatap muka dalam kegiatan siaran dakwah di radio siaran, yang dilakukan tidak hanya di studio radio tapi juga dilakukan di ruang utama Masjid Raya At Taqwa dalam kegiatan Geladak Ramadhan, dimana para narasumber bertemu langsung dengan jamaah masjid yang tentunya juga sebagai pendengar siaran geladak di Radio Maritim 102,6 FM. Mendekatkan para ustadz dan da'i serta narasumber dengan pendengar radio siaran, menjadi bukti bahwa radio siaran masih memiliki kekuatan sebagai media pendidikan dan dakwah di era melenial jaman now ini, dengan membangun ideologi penyiaran menyatukan dua salauran komunikasi yang berbeda tetapi memiliki visi yang sama, Radio Duplek 
menyatukan yang beda jadi satu tujuan. diadakan di Masjid At-Taqwa.

Berikut jadwal program Geladak yang

Gelaran Dakwah At Taqwa Bulan OKTOBER 2018

\begin{tabular}{|c|c|c|c|}
\hline Tgl & Hari & Nara Sumber & Kajian \\
\hline 1 & Senin & Drs. H. Muchlis, M.Pd & Mengukur Taqwa \\
\hline 2 & Selasa & Drs. HM. Ishomuddin AB, MBA & Kajian Akhlaq \\
\hline 3 & Rabu & Drh. H. Bambang Irianto, MBA & Budaya Cirebon \\
\hline 4 & Kamis & HM. Utsmani, M.HI & Hukum Islam \\
\hline 5 & Jum'at & H. A. Yani, M.Ag \& Ayi N. M.MPd & Keluarga Sakinah \\
\hline 6 & Sabtu & KH. Jaelani Said, M.Ag & Tasawuf \\
\hline 8 & Senin & dr. Hj. Junny Setyawati, M.Kes & Kesehatan Remaja \\
\hline 9 & Selasa & Maulidya Ulafah, M.Pd.I & Islamic Parenting \\
\hline 10 & Rabu & DR. Rhopan Safari Hasyim, M.Hum & Islam Cirebon \\
\hline 11 & Kamis & HM. Utsmani, M.HI & Hukum Islam \\
\hline 12 & Jum'at & H. A Yani, M.Ag \& Ayi N. M.MPd & Keluarga Sakinah \\
\hline 13 & Sabtu & Maya Damayanti, S.St, MH.Kes & Gizi Keluarga \\
\hline 15 & Senin & Bambang Tri Kuntara, M.Kes & Kesehatan Masyarakat \\
\hline 16 & Selasa & Jemi Naitboho, MSi & Kajian Hati \\
\hline 17 & Rabu & Drh. RH. Bambang Irianto, MBA & Budaya Cirebon \\
\hline 18 & Kamis & HM. Utsmani, M.HI & Kajian Hukum Islam \\
\hline 19 & Jum'at & H. A Yani, M.Ag \& Ayi N. M.MPd & Keluarga Sakinah \\
\hline 20 & Sabtu & KH. Jaelani Said, M.Ag & Tasawuf \\
\hline 22 & Senin & Syaeful Badar, MA & Akhlak Sosial \\
\hline 23 & Selasa & Maulidya Ulafah, M.Pd.I & Kajian Akhlaq \\
\hline 24 & Rabu & Dr. Rhopan Safari Hasyim, M.Hum & Islam Cirebon \\
\hline 25 & Kamis & HM. Utsmani, M.HI & Kajian Hukum Islam \\
\hline 26 & Jum'at & H. A Yani, M.Ag \& Ayi N. M.MPd & Keluarga Sakinah \\
\hline 27 & Sabtu & Drs. H. Muchlis, MPd & Akhlaq Tasawuf \\
\hline 29 & Senin & Dr. H. Syahrudin MA & Sikap Toleransi \\
\hline 30 & Selasa & Drs. HM. Ishomuddin AB, MBA & Kajian Akhlaq \\
\hline 31 & Rabu & Drh. R. H. Bambang Irianto, MBA & Budaya Cirebon \\
\hline
\end{tabular}

Gelaran Dakwah At Taqwa Bulan NOPEMBER 2018

\begin{tabular}{|c|l|l|l|}
\hline Tgl & Hari & \multicolumn{1}{|c|}{ Nara Sumber } & \multicolumn{1}{|c|}{ Kajian } \\
\hline 1 & Kamis & HM. Utsmani, M.HI & Kajian Hukum Islam \\
\hline 2 & Jum'at & H. A. Yani, M.Ag \& Ayi N. M.MPd & Kajian Keluarga Sakinah \\
\hline 3 & Sabtu & KH. Jaelani Said, M.Ag & Tasawuf \\
\hline 5 & Senin & dr. Hj. Junny Setyawati, M.Kes & Kesehatan Reproduksi \\
\hline 6 & Selasa & Maulidya Ulfah, MPd.I & Islamic Parenting \\
\hline 7 & Rabu & Dr. Rhopan Safari Hasyim, M. Hum & Islam Cirebon \\
\hline 8 & Kamis & HM. Utsmani, MHI & Hukum Islam \\
\hline 9 & Jum'at & H. A Yani, M.Ag \& Ayi N. M.MPd & Keluarga Sakinah \\
\hline 10 & Sabtu & Maya Damayanti, S.St. MH.Kes & Gizi Keluarga \\
\hline 12 & Senin & Bambang Tri Kuntara, M.Kes & Kesehatan Masyarakat \\
\hline 13 & Selasa & Drs. HM. Ishomuddin AB, MBA & Kajian Akhlaq \\
\hline 14 & Rabu & Drh. RH. Bambang Irianto, MBA & Budaya Cirebon \\
\hline 15 & Kamis & HM. Utsmani, M.HI & Kajian Hukum Islam \\
\hline 16 & Jum'at & H. Ahmad Yani, M.Ag \& Ayi N, M.MPd & Kajian Keluarga Sakinah \\
\hline 17 & Sabtu & Drs. H. Mukhlis, M.Pd & Mengukur Iman \\
\hline 19 & Senin & Dr. H. Syahrudin, MA & Islam Nusantara \\
\hline 20 & Selasa & Maulidya Ulfah, MPd.I & Islamic Parenting \\
\hline 21 & Rabu & Dr. Rhopan Safari Hasyim, M. Hum & Islam Cirebon \\
\hline 22 & Kamis & HM. Utsmani, M.HI & Kajian Hukum Islam \\
\hline 23 & Jum'at & H. A Yani, M.Ag \& Ayi N. M.MPd & Keluarga Sakinah \\
\hline 24 & Sabtu & Maya Damayanti, S.St. MH.Kes & Gizi Keluarga \\
\hline
\end{tabular}




\begin{tabular}{|l|l|l|l|}
\hline 26 & Senin & Syaeful Badar, MA & Islam Aktual \\
\hline 27 & Selasa & Jemi Naitboho, S.Sos, MSi & Syukur Nikmat \\
\hline 28 & Rabu & Drh. Bambang Irianto, MBA & Budaya Cirebon \\
\hline 29 & Kamis & HM. Utsmani. HS, M.HI & Kajian Hukum Islam \\
\hline 30 & Jum'at & H. A Yani, M.Ag \& Ayi N. M.MPd & Keluarga Sakinah \\
\hline
\end{tabular}

Gelaran Dakwah At Taqwa Bulan DESEMBER 2018

\begin{tabular}{|c|c|c|c|}
\hline Tgl & Hari & Nara Sumber & Kajian \\
\hline 1 & Sabtu & Dr. H. Syahruddin, MA & Hakekat dan Ma'rifat \\
\hline 3 & Senin & dr. Hj. Junny Setyawati, M.Kes & Kesehatan Reproduksi \\
\hline 4 & Selasa & Maulidya Ulfah, MPd.I & Islamic Parenting \\
\hline 5 & Rabu & Dr. Rhopan Safari Hasyim, M. Hum & Budaya Cirebon \\
\hline 6 & Kamis & HM. Utsmani. HS, M.HI & Kajian Hukum Islam \\
\hline 7 & Jum'at & H. A Yani, M.Ag \& Ayi N. M.MPd & Keluarga Sakinah \\
\hline 8 & Sabtu & Maya Damayanti, S.St. MH.Kes & Gizi Keluarga \\
\hline 10 & Senin & Bambang Tri Kuntara, M.Kes & Kesehatan Masyarakat \\
\hline 12 & Selasa & Drs. HM. Ishomuddin AB, MBA & Hak dan Kewajban Anak \\
\hline 12 & Rabu & Drh. RH. Bambang Irianto, MBA & Budaya Cirebon \\
\hline 13 & Kamis & HM. Utsmani. HS, M.HI & Kajian Hukum Islam \\
\hline 14 & Jum'at & H. A Yani, M.Ag \& Ayi N. M.MPd & Keluarga Sakinah \\
\hline 15 & Sabtu & KH. Jaelani Said, M.Ag & Dzikir dan Fikir \\
\hline 17 & Senin & Drs. H. Muchlis, M.Pd & Mengukur Ikhlas \\
\hline 18 & Selasa & Maulidya Ulfah, MPd.I & Islamic Parenting \\
\hline 19 & Rabu & Dr. Rhopan Safari Hasyim, M. Hum & Budaya Cirebon \\
\hline 20 & Kamis & HM. Utsmani. HS, M.HI & Kajian Hukum Islam \\
\hline 21 & Jum'at & H. A Yani, M.Ag \& Ayi N. M.MPd & Keluarga Sakinah \\
\hline 22 & Sabtu & KH. Jaelani Said, M.Ag & Tasawuf \\
\hline 24 & Senin & Syaeful Badar, MA & Islam Actual \\
\hline 25 & Selasa & Jemi Naitboho, S.Sos, MSi & Hakekat Sakit Melebur Dosa \\
\hline 26 & Rabu & Drh. RH. Bambang Irianto, MBA & Budaya Cirebon \\
\hline 27 & Kamis & HM. Utsmani. HS, M.HI & Kajian Hukum Islam \\
\hline 28 & Jum.at & H. A Yani, M.Ag \& Ayi N. M.MPd & Keluarga Sakinah \\
\hline 29 & Sabtu & Drs. H. Mukhlis, MPd & Koreksi Akhir Tahun \\
\hline 31 & Senin & Syaeful Badar, MA & Islam Aktual \\
\hline
\end{tabular}

\section{Keterangan :}

1. Ceramah dalam bentuk Live di Studio Radio Dakwah Masjid Raya At Taqwa di siarkan padajam 16.30 s.d 18.00 (Magrib) malalui Radio Maritim 102,6 FM. Inter Aktif dengan pendengar.

2. Narasumber diperkenankan membuat daftar pertanyaan untuk diberikan ke Pemandu acara.

Jika Berhalangan Hub: Sy. Badar HP 08122206721 dan Ade HP.0896 98461063

Programa Radio (Manual Pelatihan Media). AIBD : Asia-Pacific

DAFTAR PUSTAKA

UU Nomer 32 Tahun 2002 Tentang Penyiaran, Sinar Grafika, Jakarta, 2003

UU Nomer 36 Tahun 1999 Tentang Telekomunikasi, Sinar Grafika, Jakarta, 2000

UU Nomer 40 Tahun 1999 Tentang Pers, Nuansa Mulia, Bandung, 2005
Institute For Broadcasting Development (Institut

Pengembangan Penyiaran Asia Pasifik), Malaysia, 1999

Broadcasting Radio (Panduan Teori dan Praktek), A. Lus Y. Triartanto, Pusataka Book Publisher, Jakarta, 2010.

Annual Report, Geladak, Cirebon, 2018. 